\title{
Shotgun metagenomic analysis of metabolic diversity and microbial community structure in experimental vernal pools subjected to nitrate pulse
}

Sarah R Carrino-Kyker ${ }^{1,2^{*}}$, Kurt A Smemo ${ }^{1,3}$ and David J Burke $e^{1,2}$

\begin{abstract}
Background: Human activities have greatly increased nitrogen $(N)$ levels in natural habitats through atmospheric $N$ deposition and nutrient leaching, which can have large effects on $\mathrm{N}$ cycling and other ecosystem processes. Because of the significant role microorganisms play in $\mathrm{N}$ cycling, high inputs of nitrogenous compounds, such as nitrate $\left(\mathrm{NO}_{3}{ }^{-}\right.$), into natural ecosystems could have cascading effects on microbial community structure and the metabolic processes that microbes perform. To investigate the multiple effects of $\mathrm{NO}_{3}{ }^{-}$pollution on microbial communities, we created two shotgun metagenomes from vernal pool microcosms that were either enriched with a solution of $10 \mathrm{mg} \mathrm{NO}_{3}{ }^{-} \mathrm{N}\left(+\mathrm{NO}_{3}{ }^{-}\right)$or received distilled water as a control $(-\mathrm{N})$.
\end{abstract}

Results: After only 20 hours of exposure to $\mathrm{NO}_{3}{ }^{-}$, the initial microbial community had shifted toward one containing a higher proportional abundance of stress tolerance and fermentation environmental gene tags (EGTs). Surprisingly, we found no changes to $\mathrm{N}$ metabolism EGTs, even though large shifts in denitrification rates were seen between the $+\mathrm{NO}_{3}-$ and $-\mathrm{N}$ microcosms. Thus, in the absence of $\mathrm{NO}_{3}{ }^{-}$addition, it is plausible that the microbes used other respiratory pathways for energy. Respiratory pathways involving iron may have been particularly important in our $-\mathrm{N}$ microcosms, since iron acquisition EGTs were proportionally higher in the $-\mathrm{N}$ metagenome. Additionally, we noted a proportional increase in Acidobacteria and Alphaproteobacteria EGTs in response to $\mathrm{NO}_{3}{ }^{-}$addition. These community shifts in were not evident with TRFLP, suggesting that metagenomic analyses may detect fine-scale changes not possible with community profiling techniques.

Conclusions: Our results suggest that the vernal pool microbial communities profiled here may rely on their metabolic plasticity for growth and survival when certain resources are limiting. The creation of these metagenomes also highlights how little is known about the effects of $\mathrm{NO}_{3}^{-}$pollution on microbial communities, and the relationship between community stability and function in response to disturbance.

Keywords: Nitrate, Metagenome, 454 Sequencing, Environmental gene tag, Microcosm

\footnotetext{
* Correspondence: sarahrkyker@gmail.com

'The Holden Arboretum, Kirtland, OH, USA

${ }^{2}$ Department of Biology, Case Western Reserve University, Cleveland,

$\mathrm{OH}$, USA

Full list of author information is available at the end of the article
} 


\section{Background}

Human activities, particularly agricultural practices and fossil fuel emissions, have greatly increased inputs of nitrogen $(\mathrm{N})$ to terrestrial and aquatic habitats [1]. In agricultural regions, $\mathrm{N}$ is leached from soil in the form of nitrate $\left(\mathrm{NO}_{3}^{-}\right)$, which is often found in high concentrations in groundwater and groundwater-fed surface waters $[2,3]$. Moreover, high $\mathrm{NO}_{3}-$ in surface runoff is often observed when fertilizer is used $[4,5]$. These sources of $\mathrm{NO}_{3}{ }^{-}$ pollution pose a particular threat to aquatic habitats where groundwater and surface runoff are a significant or primary source of input. Vernal pools are temporary aquatic habitats that are common to temperate regions and filled by surface runoff following snowmelt, spring rain, and rising water table [6]. As such, $\mathrm{N}$ enrichment from $\mathrm{NO}_{3}{ }^{-}$ leaching can alleviate $\mathrm{N}$ limitation and have a significant influence on $\mathrm{N}$ cycling. Because vernal pools are shallow depressions that often experience low dissolved oxygen concentrations [7-9], increased $\mathrm{NO}_{3}{ }^{-}$availability can favor anaerobic $\mathrm{N}$ cycling processes, such as denitrification and anaerobic ammonium oxidation, while suppressing anoxic pathways adapted to low $\mathrm{NO}_{3}{ }^{-}$conditions, such as dissimilatory nitrate reduction to ammonium.

$\mathrm{N}$ cycling is almost exclusively mediated by microorganisms; therefore high $\mathrm{NO}_{3}$ - inputs can influence $\mathrm{N}$ cycling and also have cascading structural effects on the microbial communities involved. By studying genes for the enzymes responsible for the conversion of $\mathrm{N}$ between oxidized and reduced forms, there have been large advances in our knowledge of microbial functional groups involved in $\mathrm{N}$ cycling $[10,11]$. However, the $\mathrm{N}$ cycle is a complex network of pathways that can share some enzymes and can also be simultaneously influenced by the input of one nitrogenous compound, such as $\mathrm{NO}_{3}^{-}$[12]. Therefore, studies which profile only one or a subset of $\mathrm{N}$ cycling enzymes may provide a limited view of how $\mathrm{NO}_{3}{ }^{-}$pollution impacts microbial processes. In addition, most previous studies on the effects of $\mathrm{NO}_{3}-$ on microbial functional genes have limited their assessment to $\mathrm{N}$ cycling genes (e.g., $[13,14])$, even though elevated $\mathrm{NO}_{3}$ is known to affect other microbial processes, such as those involved in C cycling (e.g., [15,16]). One method that could help overcome these limitations is a shotgun metagenomic approach, where multiple functional genes can be examined.

In this study, we utilized a shotgun metagenomic approach to examine the multiple effects of $\mathrm{NO}_{3}$ - addition on vernal pool microbial communities in a microcosm experiment [17]. Two metagenomes were created, one for replicate microcosms that received $\mathrm{NO}_{3}{ }^{-}$(labeled $+\mathrm{NO}_{3}{ }^{-}$) and one for replicate microcosms where $\mathrm{NO}_{3}{ }^{-}$was not added (labeled $-\mathrm{N}$ ). Our previous study using these microcosms found that the addition of $\mathrm{NO}_{3}$ - increased denitrification, while denitrification was not detected in the absence of $\mathrm{NO}_{3}-$ [17]. This functional change was not accompanied by any change in the denitrifier community structure, which was profiled with the nos $Z$ gene using terminal restriction fragment length polymorphism (TRFLP) [17]. It is unclear, however, if this lack of response by the denitrifying community was physiological in nature or related to our functional gene choice. For the shotgun metagenomic method utilized here, the microbial genomes were randomly amplified, thus allowing for the potential inclusion of multiple $\mathrm{N}$ cycling genes, as well as genes involved in other microbial processes. In addition to denitrifier community structure, our previous analyses used TRFLP to profile the structure of general bacteria and fungi, which also did not respond to $\mathrm{NO}_{3}$ - addition [17]. Because shotgun metagenomes also provide taxonomic information for microbial communities, we hypothesized that inclusion of more than one functional gene and obtaining taxonomic composition using a shotgun metagenomic approach would reveal community structural responses to $\mathrm{NO}_{3}{ }^{-}$pulses not observed with the profiling technique, TRFLP.

\section{Results}

For the $+\mathrm{NO}_{3}-$ metagenome, there were 28,688 DNA fragments for a total of 9,085,193 bp and an average sequence length of $316 \mathrm{bp}$. The $-\mathrm{N}$ metagenome contained a larger number of DNA fragments with 81,300 and a total sequence length of 30,630,623 bp with an average fragment size of $376 \mathrm{bp}$. The metagenomes were uploaded to the Meta Genome Rapid Annotation of Sequence Technology (MG-RAST) server [18] and were analyzed unassembled with a BLASTX comparison to the SEED subsystems [19], which provided both taxonomic composition and metabolic functions. After applying our filters of $10^{-5}$ or lower e-value and $50 \mathrm{bp}$ or greater sequence similarity, 7,406 sequences $\left(+\mathrm{NO}_{3}{ }^{-}\right)$and 14,063 sequences $(-\mathrm{N})$ from the metagenomes matched with subsystems following the BLASTX analysis. The number of sequence matches to taxa with the BLASTX comparison were 6,342 $\left(+\mathrm{NO}_{3}{ }^{-}\right)$ and 12,241 $(-\mathrm{N})$. Each of these characterized DNA fragments represented an environmental gene tag (EGT), or a short segment of a gene found in the microcosm samples. The MG-RAST output included metabolic functions at four different levels, with subsystem category as the highest level and a specific gene as the lowest (see Table 1 for an example). The taxonomic output included EGT matches to domain, phylum, class, order, family, genus, and species; however because of the low sequence size cutoff of $50 \mathrm{bp}$, class was the lowest taxonomic group analyzed.

Although $\mathrm{NO}_{3}{ }^{-}$addition increased denitrification rate $\left(\right.$ mean $=3.84 \pm 0.44 \mathrm{mg} \mathrm{N}(\mathrm{kg} \mathrm{soil})^{-1}$ day $^{-1}$ versus not detected in the microcosms receiving distilled water), no significant differences in nitrogen metabolism EGTs were found with the BLASTX comparison to the SEED 
Table 1 Environmental gene tag (EGT) matches to lower levels in the SEED database that were significantly different with Fisher exact tests

\begin{tabular}{|c|c|c|c|c|c|}
\hline \multirow[b]{2}{*}{ Subsystem category ${ }^{1}$} & \multicolumn{3}{|l|}{ EGT match } & \multicolumn{2}{|c|}{$\begin{array}{c}\text { Proportional } \\
\text { representation (\%) }\end{array}$} \\
\hline & Level 2 & Level 3 & Function & $+\mathrm{NO}_{3}^{-}$ & $-\mathrm{N}$ \\
\hline Fatty acids, lipids, and isoprenoids & Phospholipids & $\begin{array}{l}\text { Glycerolipid and } \\
\text { Glycerophospholipid } \\
\text { Metabolism in Bacteria }\end{array}$ & Aldehyde dehydrogenase & 0.85 & 0 \\
\hline Fatty acids, lipids, and isoprenoids & Isoprenoids & & & 1.04 & 0.49 \\
\hline Iron acquisition and metabolism & $\begin{array}{l}\text { Iron acquisition } \\
\text { in Vibrio }\end{array}$ & - & TonB-dependent receptor & 0 & 0.75 \\
\hline Stress response & Oxidative Stress & Oxidative stress & $\begin{array}{l}\text { Alkyl hydroperoxide } \\
\text { reductase subunit C-like protein }\end{array}$ & 1.22 & 0.17 \\
\hline RNA metabolism & $\begin{array}{l}\text { RNA processing } \\
\text { and modification }\end{array}$ & & & 1.66 & 2.70 \\
\hline Carbohydrates & $\mathrm{CO}_{2}$ fixation & Calvin-Benson cycle & $\begin{array}{l}\text { NAD-dependent glyceraldehyde- } \\
\text { 3-phosphate dehydrogenase }\end{array}$ & 1.55 & 0.25 \\
\hline Carbohydrates & Fermentation & $\begin{array}{l}\text { Acetyl-CoA fermentation } \\
\text { to Butyrate }\end{array}$ & & 1.88 & 1.24 \\
\hline Protein metabolism & $\begin{array}{l}\text { Protein processing } \\
\text { and modification }\end{array}$ & $\begin{array}{l}\text { G3E family of P-loop GTPases } \\
\text { (metallocenter biosynthesis) }\end{array}$ & Urease beta subunit & 0 & 0.82 \\
\hline
\end{tabular}

${ }^{1}$ The lowest significant level for each category is reported here. Only the subsystem categories that were significantly different with Fisher exact tests (see Figure 2) are reported here. See Additional file 1: Tables S1-S3 for complete results of Fisher exact tests.

database (Figure 1). Results from Fisher exact tests at all subsystem levels and a chi-square test conducted at level two indicated no statistical differences between the $\mathrm{N}$ metabolism EGTs (Additional file 1: Tables S1-S4). Of the 7,406 EGT matches to the SEED database in the $+\mathrm{NO}_{3}-$ metagenome, only 93 (1.26\%) were to nitrogen metabolism

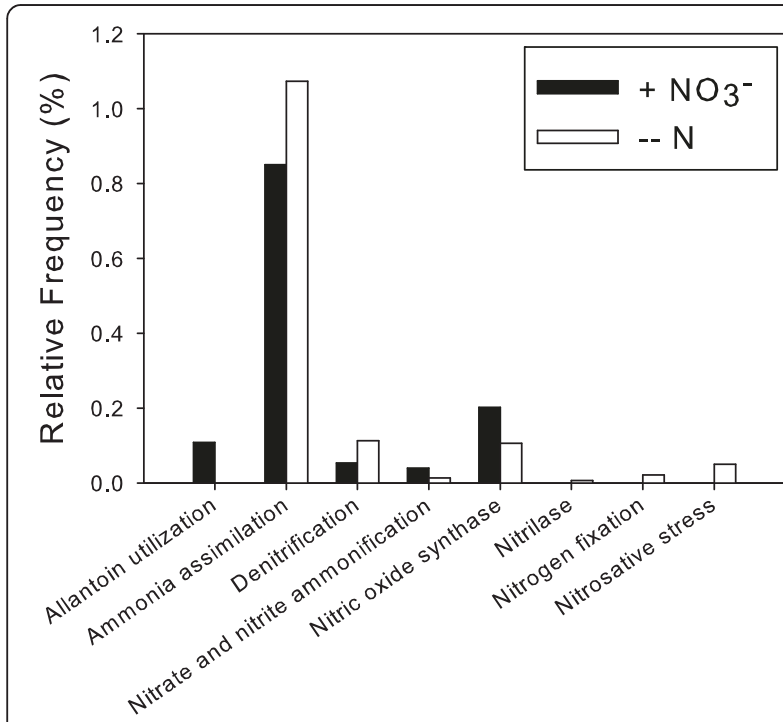

Figure 1 Subsystem matches in the nitrogen metabolism category. The proportional numbers of environmental gene tags that matched with level 2 sequences within the nitrogen metabolism subsystem category for the $+\mathrm{NO}_{3}{ }^{-}$(solid bars) and $-\mathrm{N}$ (open bars) metagenomes. No significant differences were found when these sequences were analyzed with Fisher exact tests in the Statistical Analysis of Metagenomic Profiles program. subsystems. Likewise, a low percentage of SEED database EGT matches (195 of 14,063 EGT matches; $1.39 \%$ ) were to nitrogen metabolism subsystems for the $-\mathrm{N}$ metagenome. Additional analysis of $\mathrm{N}$ metabolism EGTs was conducted with a BLASTN comparison of the metagenomes to a database of genes involved in $\mathrm{N}$ cycling pathways that we created from searches at the NCBI site. The database included genes for the enzymes involved in denitrification, dissimilatory nitrate reduction to ammonium (DNRA), anaerobic ammonium oxidation (Annamox), nitrification, and $\mathrm{N}$ fixation. (A complete list of the genes included in the database can be found in Additional file 2: Table S5). Only the $+\mathrm{NO}_{3}$ - metagenome contained matches to the $\mathrm{N}$ metabolism database with the BLASTN, which included two sequences (out of 28,688 or $0.0070 \%$ ) from the $+\mathrm{NO}_{3}-$ metagenome that matched with a number of nitrate reductase sequences (Table 2 and Additional file 2: Table S6). (All other matches in the $+\mathrm{NO}_{3}-$ metagenome and all matches to the $-\mathrm{N}$ metagenome were to genes not involved in $\mathrm{N}$ metabolism, but were picked up by our NCBI searches because they were chromosomes that also included a $\mathrm{N}$ metabolism gene that was searched for.)

EGT matches to other subsystems found with the BLASTX comparison to the SEED database, however, changed significantly between the treatments (Figure 2, Table 1, and Additional file 1: Tables S1-S4). EGTs that matched with genes in the categories of iron acquisition and metabolism, cell division and cell cycle, RNA metabolism, and protein metabolism were proportionally higher in the $-\mathrm{N}$ metagenome (Figure 2). The $+\mathrm{NO}_{3}$ - metagenome contained a higher relative number of EGT matches to 
Table 2 Nitrogen metabolism gene matches and the number of sequences from the $+\mathrm{NO}_{3}{ }^{-}$metagenome that matched with the genes, as determined with a BLASTN comparison

\begin{tabular}{cccccc}
\hline Query sequence $^{1}$ & N Metabolism gene & \# Database sequences & Average\%ID & Average alignment length & Average E-value \\
\hline$+\mathrm{NO}_{3}{ }^{-}$seq. & napA & 3 & 92.83 & 65 & $7.33 \mathrm{E}-18$ \\
$+\mathrm{NO}_{3}{ }^{-}$seq. 2 & napA & 125 & 83.83 & 131.29 & $9.86 \mathrm{E}-08$ \\
& napB & 1 & 82.35 & 119 & $4.00 \mathrm{E}-11$ \\
\hline
\end{tabular}

${ }^{1}$ The query sequence indicates that only two sequences out of 28,688 in the $+\mathrm{NO}_{3}{ }^{-}$metagenome matched with sequences in the $\mathrm{N}$ metabolism database. Seq. 1 matched with three database entries, while seq. 2 matched with 126 database entries.

genes in the fatty acids, lipids, and isoprenoids, stress response, and carbohydrates categories (Figure 2). Lower level metabolic EGT matches within these categories that were significantly different between the metagenomes are listed in Table 1.

At the phylum level, EGT matches to Acidobacteria, Proteobacteria, Actinobacteria, and Virrucomicrobia in the domain Bacteria and Streptophyta in the domain Eukaryota were proportionally higher in the $+\mathrm{NO}_{3}$ metagenome (Figure 3). EGT matches to the phyla Bacteroidetes, Firmicutes, and Chlamydiae in the domain Bacteria, to Euryarchaeota and Thaumarchaeota in the domain Archaea, and to Ascomycota and Arthropoda in the domain Eukaryota were proportionally higher in the $-\mathrm{N}$ metagenome (Figure 3). Significant differences between the metagenome taxa were also deduced at the class level to specifically examine differences within the Proteobacteria phylum (Figure 4). EGT matches to Alphaproteobacteria and Deltaproteobacteria were proportionally higher in the $+\mathrm{NO}_{3}^{-}$metagenome, while matches to Gammaproteobacteria were relatively higher in the $-\mathrm{N}$ metagenome (Figure 4).

\section{Discussion}

Metagenomic analysis revealed treatment differences both for functional and taxanomic EGTs between our $+\mathrm{NO}_{3}-$ and $-\mathrm{N}$ metagenomes. These differences were apparent even though the metagenome sequencing conducted here returned a lower number of sequences than are typically reported for shotgun metagenome studies [20-22]. However, a shotgun metagenomic sequencing effort conducted by Fierer et al. [23], where comparable sequence numbers to ours are reported, was able to elucidate increases in functional genes with increased $\mathrm{N}$ fertilization, suggesting that our sequence numbers are adequate for determining relative metabolic and taxonomic changes.

A somewhat surprising result was no proportional abundance change in any of the N metabolism EGTs between our treatments with the BLASTX comparison to the SEED database. Particularly surprising was no change in the denitrification EGTs (determined with the BLASTX) between treatments and no detection of denitrification genes with the BLASTN, other than two sequence matches to nitrate reductase in the $+\mathrm{NO}_{3}$ - treatment. The two sequence matches with the BLASTN in the $+\mathrm{NO}_{3}-$ metagenome were to the nitrate reductase genes napA and napB. Because the periplasmic nitrate reductases, which are the products of napA and napB, are used in both denitrification and DNRA [12], no conclusions can be drawn on which of these microbial groups grew to a level where they could be detected in the $+\mathrm{NO}_{3}-$ microcosms. This lack of EGT response was despite the fact that we observed denitrification rate responses to our treatments [17], where the microcosms receiving $\mathrm{NO}_{3}$ - displayed a denitrification rate near or higher than the upper range of what has been measured in flooded soils in the field [24]. This result is consistent

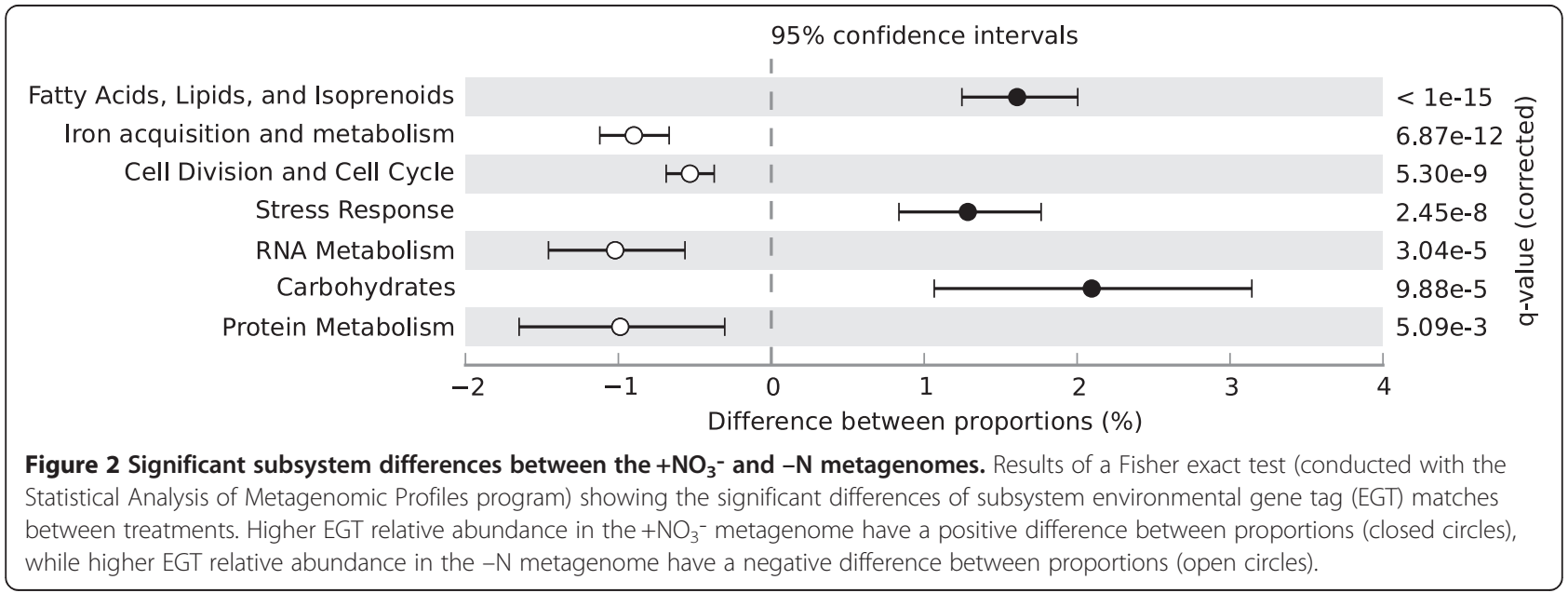




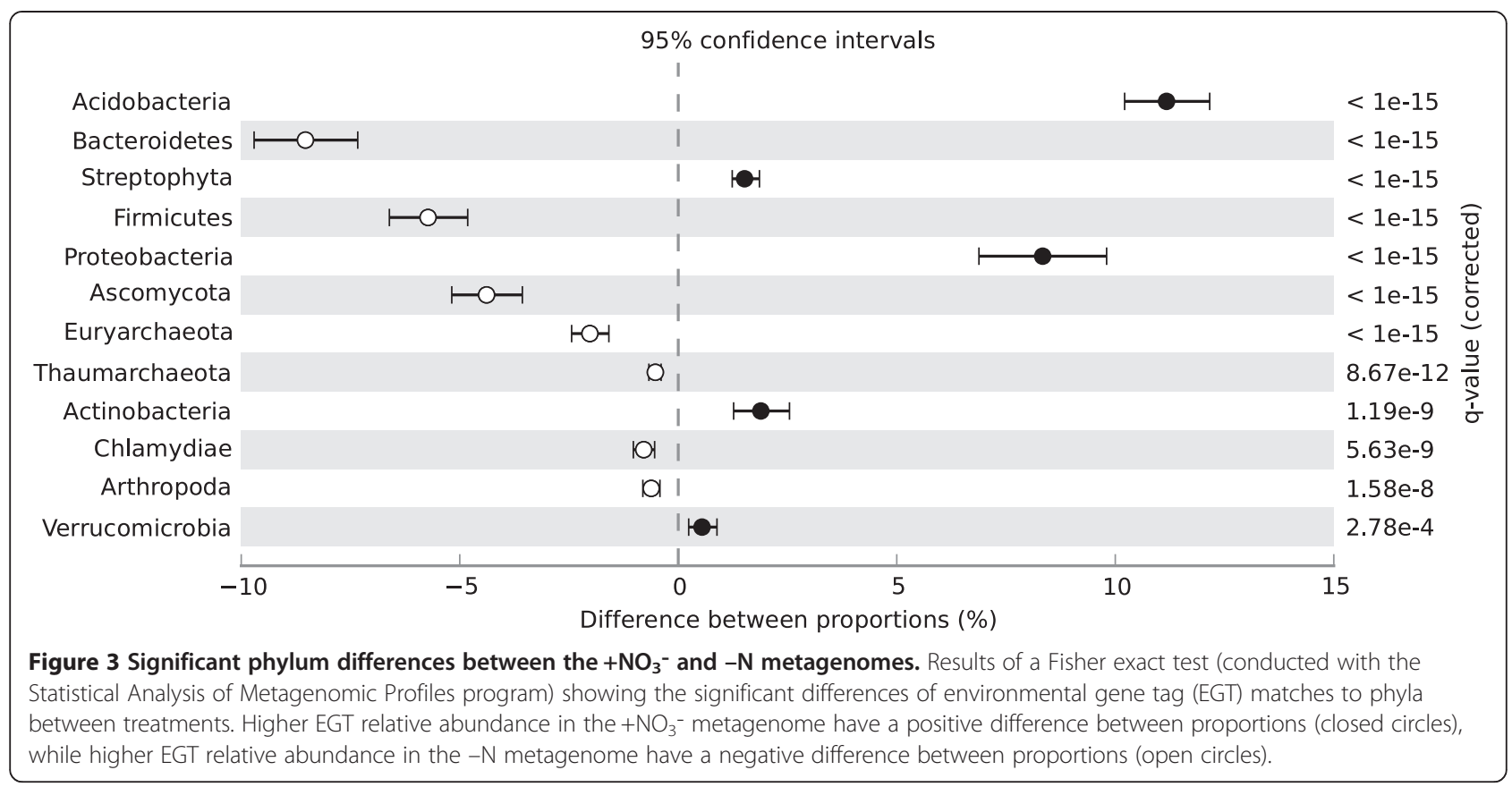

with a number of other studies that have found no link between function (including measurements of denitrification rate and denitrifying enzyme activity) and denitrifier gene copy number using QPCR [13,25-27]. We previously suggested that, in the absence of $\mathrm{NO}_{3}$ - addition, denitrifiers in our microcosms used other electron acceptors for respiration when $\mathrm{NO}_{3}$ - was not available [17], since denitrifiers are known to use other respiratory pathways [see review 10]. There were proportionally higher EGTs in the iron acquisition and metabolism category in the $-\mathrm{N}$ metagenome, and the specific EGT match was to a TonB-dependent receptor (Table 1). TonB-dependent receptors are a category of energy-coupling proteins, which are known to be involved in iron uptake by members of the genus Pseudomonas [28,29], and there is some evidence that one specific TonB-dependent receptor is involved in dissimilatory iron reduction by Shewanella oneidensis [30]. This suggests that the microbial community in the $-\mathrm{N}$ microcosms contained a greater number of organisms capable of acquiring iron and, perhaps, utilizing

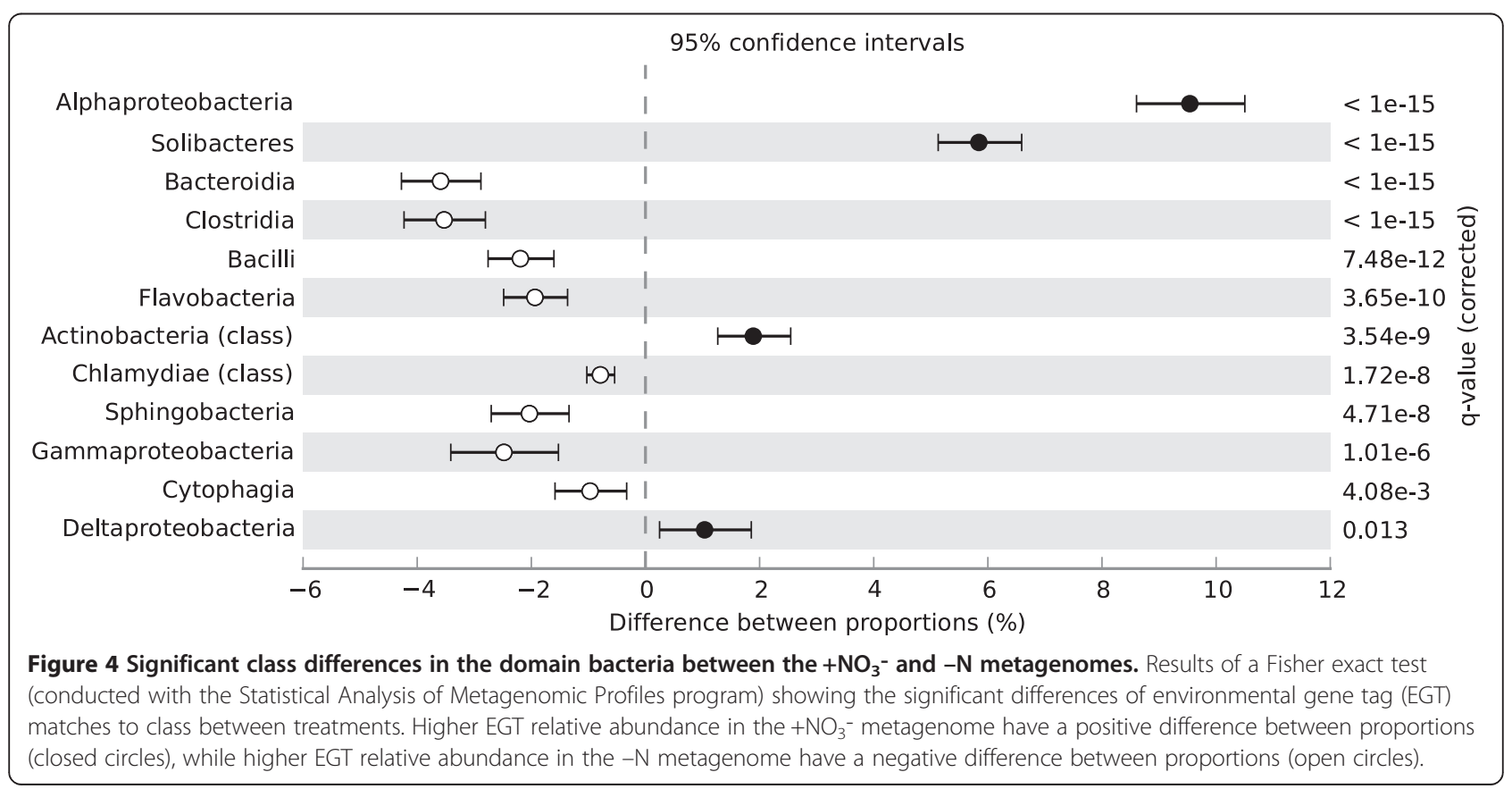


it for energy, which may have been a potential survival strategy in the absence of the $\mathrm{NO}_{3}$ - addition. To our knowledge, evidence to support this hypothesis is sparse (but see Hauck et al. [31], who found that denitrifiers can also perform anaerobic ferrous iron oxidation). It is accepted, however, that denitrifying organisms primarily perform aerobic respiration and then switch to denitrification under anoxic conditions where $\mathrm{NO}_{3}{ }^{-}$supply is sufficient [32]. There is a category available through MG-RAST for respiration genes. There were close to 400 EGT matches from the two metagenomes to this category for genes involved in both aerobic and anaerobic respiratory pathways. However, there were no proportional changes in respiration EGT abundance between the $+\mathrm{NO}_{3}-$ and the $-\mathrm{N}$ conditions (data not shown), likely because the microcosms were made anoxic prior to the metagenome creation, which could negate any advantage to aerobic organisms in either treatment. Though we did not observe proportional changes for EGTs involved in a known alternative respiratory pathway for denitrifiers, the observed proportional increase in iron acquisition and metabolism EGTs in the $-\mathrm{N}$ metagenome suggests that iron might be biogeochemically important under anoxic N-limited conditions.

Another possible reason for lack of denitrifier EGT treatment response is that denitrifiers may have been in low abundance compared to other microbial groups, making changes to their population undetectable relative to the background population numbers. For example, the denitrification gene nos $Z$ is known to be in low abundance compared to $16 \mathrm{~S}$ genes [33], and there are estimates that only $0.1-5 \%$ of culturable soil bacterial species can carry out denitrification [34]. This conclusion is supported by our BLASTN results, which found only two sequences from either metagenome that matched with a $\mathrm{N}$ metabolism gene. With the BLASTX comparison to the SEED database, however, over $1 \%$ of our sequences from each metagenome matched with nitrogen metabolism subsystems. The fact that we found no differences in nitrogen metabolism EGT relative abundance after $\mathrm{NO}_{3}{ }^{-}$addition suggests that microbial populations involved in $\mathrm{N}$ cycling did not shift in the 20 hours following exposure to a $\mathrm{NO}_{3}-$ pulse. This lack of treatment response could be due to insufficient time between treatment initiation and sampling (i.e. populations were slow to respond to the treatment). However, we did see other EGT changes, suggesting that some microbial populations grew and experienced a detectable community shift in response to acute changes in $\mathrm{NO}_{3}-$ concentration. The initial microbial community response to $\mathrm{NO}_{3}$ - in our metagenomes was toward organisms that contained stress response, carbohydrate, and fatty acids, lipids, and isoprenoid EGT matches (Figure 1). The stress response EGT that was higher in the $+\mathrm{NO}_{3}-$ metagenome was for an alkyl hydroperoxide reductase subunit C-like protein. The gene for alkyl hydroperoxide reducates, subunit $\mathrm{C}$ is upregulated by $\mathrm{NO}_{3}$ - exposure after only 30 minutes in Desulfovibrio vulgaris, suggesting that such increases in this and other oxidative stress genes may be a general stress response by the bacteria [35]. Within the carbohydrates category, one EGT match that was higher in the $+\mathrm{NO}_{3}-$ metagenome was for fermentation. Recently, there has been evidence for fermentation that is coupled to $\mathrm{NO}_{3}-$ reduction in both bacteria and fungi $[36,37]$. Fermentation in the $+\mathrm{NO}_{3}-$ microcosms may have been particularly prominent for the fungi, because a switch to $\mathrm{NO}_{3}{ }^{-}$-coupled fermentation as the primary source of energy for soil fungi under anoxic conditions has been suggested [36].

The sequencing effort described here also showed changes to the proportional representation of taxonomic EGTs. There were highly significant increases in the relative abundance of Alphaproteobacteria and Acidobacteria EGTs in the $+\mathrm{NO}_{3}$ - metagenome. Similarly, using freshwater microcosms, Barlett and Leff [38] found an increase in Alphaproteobacteria abundance when $\mathrm{NO}_{3}{ }^{-}$was present as a $\mathrm{N}$ source and suggested a competitive advantage to this group of organisms under these conditions. Under anoxic conditions, such as our microcosms, higher physiological activity and substrate uptake have been reported in several Alphaproteobacteria species when $\mathrm{NO}_{3}^{-}$or $\mathrm{NO}_{2}$ - were present as an electron acceptor [39]. Therefore, in our microcosms, there could have been a competitive advantage to the Alphaproteobacteria due to greater growth compared to other facultative organisms in an anoxic environment with abundant $\mathrm{NO}_{3}$-. To our knowledge, there have been no other studies that found such an increase in Acidobacteria with $\mathrm{NO}_{3}{ }^{-}$addition. However, a sequencing effort in cultured strains of Acidobacteria recently found that these organisms possess $\mathrm{NO}_{3}^{-}$and $\mathrm{NO}_{2}{ }^{-}$reducing genes [40]. Alphaproteobacteria [41], and likely Acidobacteria [40], are adapted to low nutrient conditions. While this seems counterintuitive to our microcosm study, vernal pools in nature are known to be oligotrophic [7]. The Alphaproteobacteria and Acidobacteria in vernal pools, then, may be adapted to survival in the disturbed, low nutrient conditions of these habitats and once $\mathrm{NO}_{3}$ - becomes readily available they have a competitive advantage due to their growth capabilities in the presence of $\mathrm{NO}_{3}-$.

These taxonomic changes were not found in a previous examination of general bacteria or general fungi in these microcosms with TRFLP [17]. The metagenomic analysis reported here provides a greater resolution than TRFLP, which is a coarse community profiling tool. Therefore, there may have been fine-scale changes in bacterial community structure that were not detected with TRFLP. Another reason for this discrepancy is that our previous TRFLP analyses used the gene regions of bacterial $16 \mathrm{~S}$ and fungal ITS for profiling [17] and, in the current study, a nonredundant protein database was used for taxonomic 
comparisons. Therefore, the conclusions drawn here regarding taxonomic changes may be limited to the taxonomic groups that changed functionally. The fact that whole genome amplification (WGA) was used prior to 454 sequencing could also be contributing to the differences seen between the metagenomes that were not noted with TRFLP. This is because amplification techniques with the Phi29 DNA polymerase, which was used in the current study, have been shown to exclude the amplification of certain DNA sequences, particularly those in low abundance or those that are GC rich, and can skew the representation of certain OTUs compared to sequencing efforts of nonamplified DNA of the same sample [42-44]. Additionally, our study design cannot exclude the possibility that the communities changed between the treatments over the 30 day incubation period prior to our sample collection. Thus, differences seen between the metagenomes may not be only because of the $\mathrm{NO}_{3}{ }^{-}$addition, but could also be due to an incubation period that changed the communities in the separate microcosms. There were six replicate microcosms to help control for variability between each jar, and our previous TRFLP profiling of the bacterial and fungal communities and the nos $Z$ gene showed no differences in community structure between the $+\mathrm{NO}_{3}{ }^{-}$and $-\mathrm{N}$ microcosms [17]. Therefore, we expect community changes in response to the 30 day incubation to be minimal compared to the $\mathrm{NO}_{3}{ }^{-}$addition. Nevertheless, the observed proportional increase in Alphaproteobacteria and Acidobacteria in response to $\mathrm{NO}_{3}$ - addition in the metagenomes requires more in depth study on the ecology of these groups and how they tolerate $\mathrm{NO}_{3}{ }^{-}$pollution.

\section{Conclusions}

These results suggest that $\mathrm{NO}_{3}{ }^{-}$additions to vernal pool habitats may be accompanied by relatively rapid microbial community changes at both the functional and taxonomic level. The initial community shift after only 20 hours of $\mathrm{NO}_{3}$ - exposure was toward a more stress tolerant community capable of performing fermentation and away from a community more dependant on respiratory pathways involving iron, as evidenced by higher iron acquisition EGTs in the $-\mathrm{N}$ microcosms. Surprisingly, we found no changes to $\mathrm{N}$ metabolism EGTs with the BLASTX in response to our treatments and only a two sequence increase in detection of nitrate reductase genes, despite a vast increase in denitrification rate with $\mathrm{NO}_{3}{ }^{-}$addition. Thus, in the absence of an $\mathrm{NO}_{3}$ - addition, it is plausible that denitrifying microbes used other respiratory pathways for energy and, although $\mathrm{NO}_{3}-$ addition altered their metabolic response, it did not alter or affect community structure or size. Because microbial communities are diverse, they are thought to be functionally redundant [45-47]. Our results suggest that the vernal pool microbial communities profiled here may rely on this metabolic plasticity for growth and survival when certain resources are limiting.

The construction of these metagenomes also highlights how little is known about the effects of $\mathrm{NO}_{3}-$ pollution on microbial communities, and the relationship between community stability and function in response to disturbance. Future research could begin to unravel the importance of stress tolerance and fermentation for microbial survival following short-term exposure to $\mathrm{NO}_{3}$ - . In addition, future studies on the presence of Acidobacteria, a group that is understudied as a whole, in high $\mathrm{NO}_{3}-$ conditions can also help to understand the distribution of this taxonomic group.

\section{Methods}

\section{Sample preparation}

Vernal pool microcosms were replicated in $500 \mathrm{~mL}$ glass jars by adding $50 \mathrm{~g}$ of soil collected from four vernal pools located in a temperate deciduous forest of Northeast Ohio, USA. The soil was air dried and sieved to remove extraneous matter and mixed with $50 \mathrm{~g}$ of autoclaved coarse sand to prevent excessive compaction of the soil media prior to addition to the microcosms. Each microcosm received $800 \mathrm{mg}$ of dried leaf discs on the surface of the soil media and $150 \mathrm{~mL}$ of sterile water. Throughout the experiment, the microcosms were held in an incubator with a 12/12 hour day night cycle, with temperatures between $15-17^{\circ} \mathrm{C}$ to mimic spring forest conditions. The microcosms were subjected to an initial $\mathrm{pH}$ manipulation $(5,6,7$, or 8 ) on day zero and $\mathrm{N}$ addition on day 30 (D30). This experimental design was used to simulate persistent $\mathrm{pH}$ changes previously observed in vernal pools across an urbanization gradient [7] and $\mathrm{NO}_{3}{ }^{-}$pulses that are often associated with polluted runoff [48], which can be a significant source of input into vernal pools. While the complete experiment contained 72 microcosms and full details of the experimental set up are described elsewhere [17], a subset of 12 microcosms were used for the metagenomic analysis reported here and were those that were manipulated to a $\mathrm{pH}$ of $6.0 \pm 0.3$ at the beginning of the experiment and received either an addition of $10 \mathrm{mg} \mathrm{NO}_{3}^{-}-\mathrm{N}$ or an equal volume of distilled water as a control on D30. There were six replicate microcosms for each treatment $\left(\mathrm{NO}_{3}{ }^{-}\right.$ addition and control). The $\mathrm{NO}_{3}{ }^{-}$addition and distilled water treatments were used because denitrification rate differed in these microcosms (an average of $3.84 \pm$ $0.44 \mathrm{mg} \mathrm{N}(\mathrm{kg} \mathrm{soil})^{-1}$ day $^{-1}$ when $\mathrm{NO}_{3}{ }^{-}$was added and not detected in the microcosms receiving distilled water) [17]. Two replicate soil samples were collected and pooled from each microcosm on D30 approximately 20 hours after the $\mathrm{NO}_{3}{ }^{-}$addition and frozen at $-70^{\circ} \mathrm{C}$ until used for DNA extraction. Soil samples were further pooled by combining $125 \mathrm{mg}$ of soil from two replicate microcosms in the same 
treatment and then subjecting this pooled soil sample to DNA extraction as described elsewhere [17]. Therefore, there were three replicate DNA samples for each treatment that were used to create two metagenomes: one for the nitrate treatment (labeled $+\mathrm{NO}_{3}{ }^{-}$) and one for the distilled water treatment (labeled --N).

\section{Pyrosequencing}

Similar to other shotgun metagenomic studies [20,49-51], DNA was amplified with the illustra Genomiphi V2 amplification kit (GE Healthcare Life Sciences, Inc., Piscataway, NJ) following the manufacturer's protocol. Two replicate Genomiphi reactions were prepared for each microcosm DNA sample, making six reactions total for each treatment (three replicate microcosm DNA samples $\times$ two replicate Genomiphi reactions). The Genomiphi reactions randomly amplified regions of genomic DNA using primers of random sequences and resulted in $8 \mu \mathrm{g}$ of amplified DNA from the $+\mathrm{NO}_{3}-$ sample and the $10 \mu \mathrm{g}$ of amplified DNA from the $-\mathrm{N}$ sample. Because of the use of random primers, these amplified DNA samples potentially included segments of DNA from all microbial species present in the samples and from regions throughout the microbial genomes. The amplified DNA from Genomiphi reactions was precipitated with sodium acetate and purified with $80 \%$ cold ethanol before being sent to Inqaba Biotec (Pretoria, South Africa) for 454 pyrosequencing on a GS-FLX platform.

\section{Sequence analysis}

Because the metagenomes constructed from our microcosms contained DNA reads from multiple species, they were analyzed unassembled using the MG-RAST server [18] and are publicly available with the MG-RAST ID numbers $4445106.3\left(+\mathrm{NO}_{3}{ }^{-}\right)$and $4445130.3 \quad(-\mathrm{N})$. Metagenomes are also available through the NCBI site [GenBank: SRP005560]. A BLASTX comparison to a nonredundant protein database was used to match the EGTs in the metagenomes to SEED subsystems [19]. The SEED protein-coding database has been used successfully for comparing shotgun metagenomes to taxonomic [20,21,51] and metabolic sequences [20,21,49-51] in environmental samples. Only matches that had an e-value of $10^{-5}$ or lower and had sequence similarity of 50 base pairs or greater were included in our MG-RAST analysis.

Metagenomes were also analyzed with a local BLASTN to a database of $\mathrm{N}$ metabolism genes that we constructed with searches at the NCBI site. The database included the known genes for the enzymes involved in denitrification, DNRA, and Annamox (using [12,52] as guides for the genes to include), as these processes are nitrate reduction pathways. The highly profiled functional genes for nitrification $(a m o A, a m o B$, and $a m o C)$ and nitrogen fixation (nifD, nifH, and nifK) were also included. The database contained a total of 111,502 sequences and a complete list of the genes included in the database can be found in Additional file 2: Table S5. The searches for the genes to include in the database at the NCBI site were to the "Nucleotide" collection of the International Nucleotide Sequence Database Collaboration (DDBJ/EMBL/GenBank) with limits, which excluded sequence tagged sites (STSs), third party annotation (TPA) sequences, high throughput genomic (HTG) sequences, patents, and whole genome shotgun (WGS) sequences. Additional limits were that the search field was gene name and the molecule was genomic DNA/RNA., We also excluded hits that included "complete genome" in any field. (The search field was as follows: "xxxX [Gene Name] AND biol_genomic [PROP] NOT "complete genome" [All Fields]", where "xxxX" corresponds to the gene that was being searched for, such as "nosZ".) The local BLASTN was conducted at Case Western Reserve University's Genome and Transcriptome Analysis Core facility. A number of sequences in our database were complete chromosome sequences that included genes other than the $\mathrm{N}$ metabolism genes we were interested in. If sequences from the metagenomes matched with these database entries, they were only retained if the gene region of the BLASTN match was to a N metabolism gene of interest (e.g., if the match between the metagenome sequence and the database entry was to the gene region coding for a $\mathrm{N}$ metabolism gene of interest, such as the napA gene, it was kept, but if the match was to a non- $\mathrm{N}$ metabolism gene, such as the trpS gene, it was removed.) The BLASTN comparison included an e-value cutoff of $10^{-5}$ or lower and sequence similarity cutoff of 50 base pairs or greater.

\section{Statistical analysis}

The Statistical Analysis of Metagenomic Profiles (STAMP) program was used to compare the $+\mathrm{NO}_{3}{ }^{-}$and $-\mathrm{N}$ metagenomes by identifying the proportional representation of different metabolic or phylogenetic groups and determining if they were statistically different between the two metagenomes with two-sided Fisher exact tests [53]. The MG-RAST functional matches at all levels and taxonomic matches at the class level and higher were compared with Fisher exact tests. Storey's false discovery rate (FDR) method was applied to the Fisher exact tests as a multiple comparison test correction, resulting in q-values, which are the FDR equivalent of p-values. Confidence intervals were determined with the Newcome-Wilson method at $\alpha=0.05$. Statistically significant features that had less than five sequences or low effect sizes $(<0.5$ difference between proportions or $<1.0$ ratio of proportions) were removed from the analysis. In addition, a two sided chi-square test, with Yates' correction for continuity, was conducted, also using STAMP, on the level two subsystems. This test was done specifically to investigate if any level two EGTs in the $\mathrm{N}$ metabolism category were 
statistically different with a less conservative test [53]. Confidence intervals were calculated and effect size filters were used as with the Fisher exact tests. The multiple comparison test correction used was the Benjamini-Hochberg FDR. Only biologically meaningful categories were included in the results reported here (i.e., the miscellaneous category for subsystems was removed and, for the phylogenetic EGT matches, unclassified taxonomic groups were removed).

\section{Additional files}

Additional file 1: Tables S1-S4. Results from Fisher exact tests at al subsystem levels and a chi-square test conducted at level two using the Statistical Analysis of Metagenomic Profiles program.

Additional file 2: Tables S5-S6. Nitrogen metabolism genes included in the database created from the NCBI site and all matches from the $+\mathrm{NO}_{3}{ }^{-}$ metagenome to nitrogen metabolism genes with a BLASTN.

\section{Competing interests}

The authors declare that they have no competing interests.

\section{Authors' contributions}

SC-K conceived of the study, collected and processed samples for sequencing, and authored the manuscript. KS participated in the design and implementation of the study and edited and commented on the paper. DB conceived of the study and participated in its design and implementation, contributed to data analysis, and edited and commented on the paper. All authors read and approved the final manuscript.

\section{Acknowledgements}

We thank Dr. Wendy M. Mahaney, Dr. Juan Carlos López-Gutiérrez, and Charlotte R. Hewins for help with collecting samples. Thank you also to Dr. Xiaodong Bai for his assistance with database creation and for running the local BLASTN for us and to Dr. Laurel A. Kluber for advice on data analysis. This work was funded by the Holden Arboretum Trust and the Corning Institute for Education and Research.

\section{Author details}

${ }^{1}$ The Holden Arboretum, Kirtland, OH, USA. ${ }^{2}$ Department of Biology, Case Western Reserve University, Cleveland, OH, USA. ${ }^{3}$ Department of Biological Sciences, Kent State University, Kent, OH, USA.

Received: 11 February 2013 Accepted: 1 April 2013

Published: 10 April 2013

\section{References}

1. Vitousek PM, Aber JD, Howarth RW, Likens GE, Matson PA, Schindler DW, Schlesinger WH, Tilman DG: Human alteration of the global nitrogen cycle: sources and consequences. Ecol Appl 1997, 7:737-750

2. Power JF, Schepers JS: Nitrate contamination of groundwater in north america. Agric Ecosyst Environ 1989, 26:165-187.

3. Almasri MN, Kaluarachchi JJ: Assessment and management of long-term nitrate pollution of ground water in agriculture-dominated watersheds. J Hydrol 2004, 295:225-245.

4. Owens $L B$, Edwards WM, Van Keuren RW: Peak nitrate-nitrogen values in surface runoff from fertilized pastures. J Environ Qual 1984, 13:310-312.

5. King KW, Torbert HA: Nitrate and ammonium losses from surface-applied organic and inorganic fertilizers. J Agric Sci 2007, 145:385-393.

6. Colburn EA: Vernal Pools: Natural History and Conservation. Blacksburg, VA: The McDonald \& Woodward Publishing Company; 2004.

7. Carrino-Kyker SR, Swanson AK: Seasonal physicochemical characteristics of thirty northern Ohio temporary pools along gradients of GIS-delineated human land-use. Wetlands 2007, 27:749-760.
8. Carrino-Kyker SR, Swanson AK: Temporal and spatial patterns of eukaryotic and bacterial communities found in vernal pools. Appl Environ Microbiol 2008, 74:2554-2557.

9. Carrino-Kyker SR, Swanson AK, Burke DJ: Changes in eukaryotic microbial communities of vernal pools along an urban-rural land use gradient. Aquat Microb Ecol 2011, 62:13-24

10. Philippot L, Hallin S: Molecular analyses of soil denitrifying bacteria. In Molecular Techniques for Soil, Rhizosphere and Plant Microorganisms. Edited by Cooper JE, Rao JR. Cambridge, MA: CAB International Publishing; 2006:146-165

11. Bothe H, Jost G, Schloter M, Ward BB, Witzel K-P: Molecular analysis of ammonia oxidation and denitrification in natural environments. FEMS Microbiol Rev 2000, 24:673-690.

12. Kraft B, Strous M, Tegetmeyer HE: Microbial nitrate respiration - Genes, enzymes and environmental distribution. J Biotechnol 2011, 155:104-117.

13. Kandeler E, Brune T, Enowashu E, Dörr N, Guggenberger G, Lamersdorf N, Philippot $\mathrm{L}$ : Response of total and nitrate-dissimilating bacteria to reduced $\mathrm{N}$ deposition in a spruce forest soil profile. FEMS Microbiol Ecol 2009, 67:444-454.

14. Deiglmayr K, Philippot L, Kandeler E: Functional stability of the nitratereducing community in grassland soils towards high nitrate supply. Soil Biol Biochem 2006, 38:2980-2984.

15. DeForest IL, Zak DR, Pregitzer KS, Burton AJ: Atmospheric Nitrate Deposition, Microbial Community Composition, and Enzyme Activitiy in Northern Hardwood Forests. Soil Sci Soc Am J 2004, 68:132-138.

16. Smemo KA, Zak DR, Pregitzer KS: Chronic $\mathrm{NO}_{3}{ }^{-}$deposition reduces the retention of fresh leaf litter-derived DOC in northern hardwood forests. Soil Biol Biochem 2006, 38:1340-1347.

17. Carrino-Kyker SR, Smemo KA, Burke DJ: The effects of $\mathrm{pH}$ change and $\mathrm{NO}_{3}^{-}$ pulse on microbial community structure and function: a vernal pool microcosm study. FEMS Microbiol Ecol 2012, 81:660-672.

18. Meyer F, Paarmann D, D'Souza M, Olson R, Glass EM, Kubal M, Paczian T, Rodriguez A, Stevens R, Wilke A, et al: The metagenomics RAST server - a public resource for the automatic phylogenetic and functional analysis of metagenomes. BMC Bioinforma 2008, 9:386.

19. Overbeek R, Begley T, Butler RM, Choudhuri JV, Chuang HY, Cohoon M, de Crécy-Lagard V, Diaz N, Disz T, Edwards R, et al: The subsystems approach to genome annotation and its use in the project to annotate 1000 genomes. Nucleic Acids Res 2005, 33:5691-5702.

20. Pfister CA, Meyer F, Antonopoulos DA: Metagenomic profiling of a microbial assemblage associated with the california mussel: a node in networks of carbon and nitrogen cycling. PLoS One 2010, 5:e10518.

21. Varin T, Lovejoy C, Jungblut AD, Vincent WF, Corbeil J: Metagenomic analysis of stress genes in microbial Mat communities from antarctica and the high arctic. Appl Environ Microbiol 2012, 78:549-559.

22. Gomez-Alvarez V, Revetta RP, Santo Domingo JW: Metagenomic analyses of drinking water receiving different disinfection treatments. Appl Environ Microbiol 2012, 78:6095-6102.

23. Fierer $\mathrm{N}$, Lauber $\mathrm{CL}$, Ramirez KS, Zaneveld J, Bradford MA, Knight $\mathrm{B}$ : Comparative metagenomic, phylogenetic and physiological analyses of soil microbial communities across nitrogen gradients. ISME J 2012, 6:1007-1017.

24. Groffman PM, Teidje JM: Denitrification hysteresis during wetting and drying cycles in soil. Soil Sci Soc Am J 1988, 52:1626-1629.

25. Kandeler E, Brune T, Enowashu E, Dörr N, Guggenberger G, Norbert L, Philippot L: Response of total and nitrate-dissimilating bacteria to reduced $\mathrm{N}$ deposition in a spruce forest soil profile. FEMS Microbiol Ecol 2006, 67:444-454.

26. Ma WK, Bedard-Haughn A, Siciliano SD, Farrell RE: Relationship between nitrifier and denitrifier community composition and abundance in predicting nitrous oxide emissions from ephemeral wetland soils. Soil Biol Biochem 2008, 40:1114-1123.

27. Dandie CE, Wertz S, Leclair C, Goyer C, Burton DL, Patten CL, Zebarth BJ, Trevors JT: Abundance, diversity and functional gene expression of denitrifier communities in adjacent riparian and agricultural zones. FEMS Microbiol Ecol 2011, 77:69-82.

28. Cornelis P, Badillis J: A survey of TonB-dependent receptors in fluorescent pseudomonads. Environ Microbiol Rep 2009, 1:256-262.

29. Folschweiller N, Schalk IJ, Celia H, Kieffer B, Abdallah MA, Pattus F: The pyoverdin receptor FpvA, a TonB-dependent receptor involved in iron update by Pseudomonas aeruginosa (review). Mol Membr Biol 2000, 17:123-133. 
30. Qian Y, Shi L, Tien M: SO2907, a putative TonB-dependent receptor, is involved in dissimilatory iron reduction by Shewanella oneidensis straing MR-1. J Biol Chem 2011, 286:33973-33980

31. Hauck S, Benz M, Brune A, Schink B: Ferrous iron oxidation by denitrifying bacteria in profundal sediments of a deep lake (Lake Constance). FEMS Microbiol Ecol 2001, 37:127-134.

32. Philippot L, Hallin S, Schloter M: Ecology of denitrifying prokaryotes in agricultural soil. Adv Agron 2007, 96:249-305.

33. Henry S, Bru D, Stres B, Hallet S, Philippot L: Quantitative detection of the nos $Z$ gene, encoding nitrous oxide reductase, and comparison of the abundances of $16 \mathrm{~S}$ rRNA, narG, nirK, and nosZ genes in soils. App/ Environ Microbiol 2006, 72:5181-5189.

34. Tiedje JM: Ecology of denitrification and dissimilatory nitrate reduction to ammonium. In Biology of Anaerobic Microorganisms. Edited by Zehnder AJB. New York, NY: John Wiley \& Sons, Inc; 1988:179-244.

35. He Q, He Z, Joyner DC, Joachimiak M, Price MN, Yang ZK, Yen H-CB, Hemme CL, Chen W, Fields MW, et al: Impact of elevated nitrate on sulfate-reducing bacteria: a comparative study of Desulfovibrio vulgaris. ISME J 2010, 4:1386-1397.

36. Zhou Z, Takaya N, Nakamura A, Yamaguchi M, Takeo K, Shoun H: Ammonia Fermentation, a novel anoxic metabolism of nitrate by fungi. $J \mathrm{Bio} / \mathrm{Chem}$ 2002, 277:1892-1896.

37. Seifritz C, Daniel SL, Göbner A, Drake HL: Nitrate as a preferred electron sink for the acetogen Clostridium thermoaceticum. J Bacterio/ 1993, 175:8008-8013.

38. Bartlett AF, Leff MA: The effects of N:P ration and nitrogen form on four major freshwater bacterial taxa in biofilms. Can J Microbiol 2010, 56:32-43.

39. Kragelund C, Kong Y, van der Waarde J, Thelen D, Eikelboom D, Tandoi V, Thomsen VR, Nielsen PH: Ecophysiology of different filamentous Alphaproteobacteria in industrial wastewater treatment plant. Microbiol 2006, 152:3003-3012.

40. Ward NL, Challacombe JF, Janssen PH, Henrissat B, Coutinho PM, Wu M, Xie G, Haft DH, Sait M, Badger J, et al: Three genomes from the phylum Acidobacteria provide insight into the lifestyles of these microorganisms in soils. Appl Environ Microbiol 2009, 75:2046-2056.

41. Pinhassi J, Berman T: Differential growth response of colony forming $a-$ and $y$-Proteobacteria in dilution culture and nutrient addition experiments from lake Kinneret (Israel), the eastern Mediterranean Sea, and the Gulf of Eilat. Appl Environ Microbiol 2003, 69:199-211.

42. Bodelier PLE, Kamst M, Meima-Franke M, Stralis-Pavese N, Bodrossy L: Whole-community genome amplification (WCGA) leads to compositional bias in methane-oxidizing communities as assessed by pmoA-based microarray analyses and QPCR. Environ Microbiol Rep 2009 1:434-441.

43. Yilmaz S, Allgaier M, Hugenholtz P: Multiple displacement amplification compromises quantitative analysis of metagenomes. Nat Methods 2010, 7:943-944.

44. Kim K-H, Bae J-W: Amplification methods bias metagenomic libraries of uncultured single-stranded and double-stranded DNA viruses. Appl Environ Microbiol 2011, 77:7663-7668.

45. McGrady-Steed J, Harris PM, Morin PJ: Biodiversity regulates ecosystem predictability. Nature 1997, 390:162-165.

46. Wertz S, Degrange V, Prosser J, Poly F, Commeaux C, Guillaumaud N, Le Roux X: Decline of soil microbial diversity does not influence the resistance and resilience of key soil microbial functional groups following a model disturbance. Environ Microbiol 2007, 9:2211-2219.

47. Naeem S, Li S: Biodiversity enhances ecosystem reliability. Nature 1997 390:507-509.

48. Moldan B, Cerny J: Biogeochemistry of Small Catchments. West Sussex, England: John Wiley \& Sons Ltd; 1994.

49. Dinsdale E, Pantos O, Smriga S, Edwards RA, Angly F, Wegley L, Hatay M, Hall $D$, Brown $E$, Haynes $M$, et al: Microbial ecology of four coral atolls in the Northern Line Islands. PLOS One 2008, 3:e1584.

50. Edwards RA, Rodriguez-Brito B, Wegley L, Haynes M, Breitbart M, Peterson DM, Saar MO, Alexander S, Alexander EC Jr, Rohwer F: Using pyrosequencing to shed light on deep mine microbial ecology. BMC Genomics 2006, 7:57.
51. Vega Thurber R, Willner-Hall D, Rodriguez-Mueller B, Desnues C, Edwards RA, Angly F, Dinsdale E, Kelly L, Rohwer F: Metagenomic analysis of stressed coral holobionts. Environ Microbiol 2009, 11:2148-2163.

52. Philippot $\mathrm{L}$, Hallin S: Finding the missing link between diversity and activity using denitrifying bacteria as a model functional community. Curr Opin Microbiol 2005, 8:234-239.

53. Parks DH, Beiko RG: Identifying biologically relevant differences between metagenomic communities. Bioinformatics 2010, 26:715-721.

doi:10.1186/1471-2180-13-78

Cite this article as: Carrino-Kyker et al: Shotgun metagenomic analysis of metabolic diversity and microbial community structure in experimental vernal pools subjected to nitrate pulse. BMC Microbiology 2013 13:78

\section{Submit your next manuscript to BioMed Central and take full advantage of:}

- Convenient online submission

- Thorough peer review

- No space constraints or color figure charges

- Immediate publication on acceptance

- Inclusion in PubMed, CAS, Scopus and Google Scholar

- Research which is freely available for redistribution 